\title{
The electrocardiographic diagnosis of apical infarction
}

\author{
STEPHen TALBot \\ M.B. B.S., M.R.C.P.
}

\author{
DAVID KiLPATRICK \\ M.B. Ch.B., M.R.C.P.
}

\author{
BARBARA WEEKS
}

Division of Cardiovascular Disease, Hammersmith Hospital, London

\begin{abstract}
Summary
Dyskinetic areas of the left ventriculograms of 151 patients were related to electrocardiographic signs of infarction. Apical dyskinesia alone or in combination with anterior or inferior dyskinesia could be associated with inferior and/or anterior infarction patterns. Appreciation of this fact prevents over-estimation of the severity of coronary artery disease from a resting electrocardiogram, showing both 'anterior and inferior infarction'.
\end{abstract}

\section{Introduction}

Apical dyskinesia can be distinguished from inferior and anterior dyskinesia. Inferior and anterior dyskinetic areas on left ventriculograms have been related to electrocardiographic signs of inferior and anterior infarction (Gunnar et al., 1967; Hugenholtz, Forkner and Levine, 1961). However, a similar comparison has not been made for apical dyskinesia, although vectorcardiographic studies have suggested that a superior clockwise $Q$ loop with diminished anterior forces in the left sagittal plane is typical of apical infarction (Recke, Dacians and Rudolph, 1978). In view of the widespread use of 12-lead electrocardiography a study was made of the electrocardiographic features associated with apical dyskinesia.

\section{Method}

Angiograms performed between 1975 and 1978 on patients with ischaemic heart disease were examined for the presence of dyskinesia. One hundred and ninety-five angiograms of high quality without ventricular extrasystoles, which were recorded in the right anterior oblique projection, were analysed. More than $50 \%$ occlusion was considered evidence of significant coronary arterial involvement. Both 12-lead and Frank X, Y, Z electrocardiograms of each patient were examined independently of the angiograms. Pathological $Q$ waves in all leads were

\footnotetext{
Address for reprints: S. Talbot, Clinical Cardiology' Hammersmith Hospital, London.
}

recorded, and when necessary digital vectorcardiograms were displayed (Talbot et al., 1976, 1978). The 15-lead electrocardiograms were classified as showing inferior, anterior or lateral infarction patterns or a combination of these (Talbot et al., 1976). Patients with ventricular conduction defects including extreme left axis deviation (QRS axis more negative than $-40^{\circ}$ ) were excluded. Finally, these patterns were compared to the distribution of dyskinesia and coronary artery disease.

\section{Results}

Pathological $Q$ waves were found in 160 patients with dyskinesia. However 9 of these patients had extensive anterior, apical and inferior dyskinesio with triple vessel disease and have therefore not been considered further. Of the remaining 151 patients, 37 had antero-apical dyskinesia, 46 had infero-apical dyskinesia, 48 had apical dyskinesia only, 8 had inferior dyskinesia only and 12 had anterior dyskinesia only.

Electrocardiographic evidence of inferior infarction was found in 40 patients with apical dyskinesia and similar evidence of anterior infarction was found in 18 patients (10 patients had both anterior and inferior infarction patterns). Despite the predominance of inferior infarction patterns the left anterior descending coronary artery was involved as frequently as the right (Table 1). Single right coronary artery disease was present in 8 , and isolated left anterior descending coronary artery disease in 6 patients. Double vessel disease was present in 12 patients in all of whom the left anterior descending coronary artery was involved; in only 2 of these patients was the circumflex coronary artery involved. However, the majority of the patients with isolated apical dyskinesia had triple vessel disease (18) (Table 1).

Left main stem disease is rarely associated with dyskinesia at rest and therefore not surprisingly was unusual in the entire group. Four patients with double or triple vessel disease and apical dyskinesia 
TABLE 1. Association of coronary artery disease with dyskinetic areas

\begin{tabular}{lccccc}
\hline \multicolumn{1}{c}{$\begin{array}{c}\text { Dyskinetic } \\
\text { areas }\end{array}$} & $\begin{array}{c}\text { Right coronary } \\
\text { disease }\end{array}$ & $\begin{array}{c}\text { Circumflex } \\
\text { coronary disease }\end{array}$ & $\begin{array}{c}\text { Left anterior } \\
\text { descending coronary } \\
\text { disease }\end{array}$ & $\begin{array}{c}\text { Left main } \\
\text { stem disease }\end{array}$ \\
\hline Apical & $(48)$ & 36 & 20 & 36 & 4 \\
Inferior \pm apical & $(54)$ & 54 & 45 & 50 & 0 \\
Anterior \pm apical & $(49)$ & 41 & 35 & 49 & 1 \\
\hline
\end{tabular}

only also had disease of the left main stem; in addition, one patient with anterior and apical dyskinesia had involvement of the left main stem.

Anterior dyskinesia ( \pm apical dyskinesia) was always associated with left anterior descending coronary artery disease, and inferior dyskinesia ( \pm apical dyskinesia) was always associated with right coronary artery disease (Table 1). However, in the latter condition double or triple vessel disease was universal.

By separating patients into 2 groups, i.e. apical dyskinesia \pm inferior or anterior dyskinesia (131) and those without apical dyskinesia (20), it was found there were no distinctive electrocardiographic features. This was because both inferior and anterior infarction patterns could occur with apical dyskinesia (Fig. 1). In addition, 8 patients of the 131 with apical dyskinesia had lateral infarction patterns. The only factor associated with anterior infarction patterns was electrical axis (Table 2). Thus, if the electro- cardiograms were divided into these with an electrical axis between +30 and $-40^{\circ}$, and those with an electrical axis between +30 and $+90^{\circ}$ it could be shown that apical dyskinesia was significantly more often associated with an anterior infarction pattern if the axis was horizontal $\left(+30\right.$ to $\left.-40^{\circ}\right)\left(\chi^{2}=8 \cdot 8\right.$, $\boldsymbol{P}<0.01)$. Inferior infarction patterns occurred whatever the electrical axis but unless there was inferior dyskinesia, the inferior $Q$ waves were usually $<30 \mathrm{msec}$ in duration although $\mathrm{QR}$ ratios $>25^{\circ}$ and $\mathrm{Q}$ waves in leads II, III and AVF were found.

\section{Discussion}

Lateral infarction patterns may be associated with apical dyskinesia. In particular $\mathrm{V}_{5}$ is often the lead most clearly related to the apex. However small $Q$ waves are a normal finding in this lead.

This study suggests that apical dyskinesia is usually associated with an inferior infarction pattern,

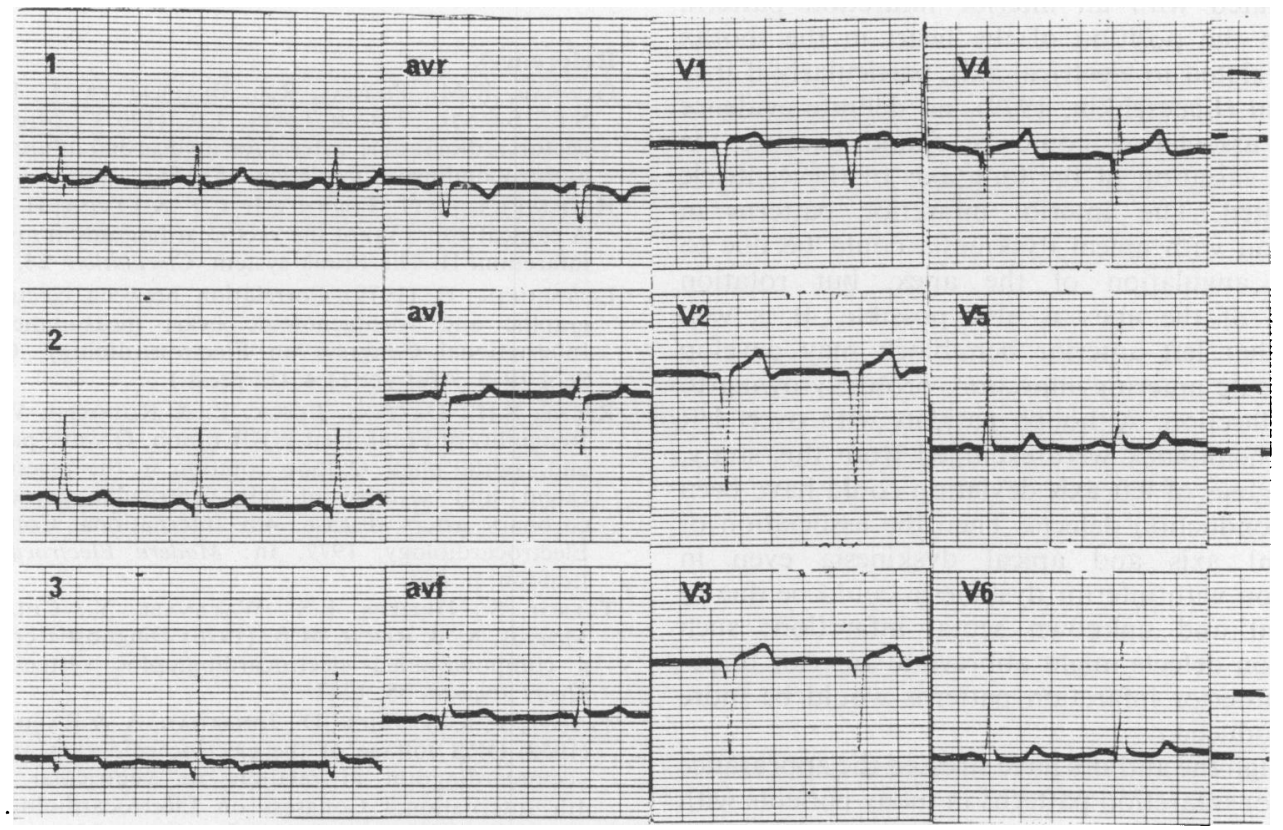

FIG. 1. Twelve lead ECG of patients with antero-apical dyskinesia due to disease of the left anterior descending coronary artery only. There are $Q$ waves in leads II, III and AVF. The $Q$ wave in lead III is $>40 \mathrm{~ms}$ in duration. In addition there are $Q S$ waves in $V_{1}$ to $V_{3}$ and a $Q R$ pattern in $V_{4}$. 
TABLE 2. The relationship of ECG infarction patterns to electrical axis

\begin{tabular}{|c|c|c|c|c|c|c|}
\hline & & \multicolumn{2}{|c|}{ Dyskinesia } & $\begin{array}{l}\text { Inferior infarct } \\
\text { (ECG) }\end{array}$ & $\begin{array}{l}\text { Anterior infarct } \\
\text { (ECG) }\end{array}$ & $\begin{array}{l}\text { Anterior/inferior } \\
\text { infarct } \\
\text { (ECG) }\end{array}$ \\
\hline \multirow{3}{*}{ QRS axis } & \multirow{3}{*}{$\begin{array}{l}\geqslant-40 \\
\leqslant+30\end{array}$} & $\begin{array}{r}\text { Apical } \\
(+ \text { Anterior/inferior) }\end{array}$ & $\begin{array}{l}51 \\
(71)^{*}\end{array}$ & 20 & ${ }^{25}(37)^{*}$ & (12) \\
\hline & & & & & & \\
\hline & & $\begin{array}{l}\text { Apical } \\
\text { Alone }\end{array}$ & 20 & 14 & 12 & \\
\hline \multirow{3}{*}{ QRS axis } & \multirow{3}{*}{$\begin{array}{l}>+30 \\
\leqslant+90\end{array}$} & $\begin{array}{r}\text { Apical } \\
(+ \text { Anterior/inferior })\end{array}$ & ${ }^{32}(60)^{*}$ & $25(51)$ & 9 & (4) \\
\hline & & $\begin{array}{l}\text { Apical } \\
\text { Alone }\end{array}$ & 28 & 26 & 6 & \\
\hline & & Totals & 131 & 95 & 52 & 16 \\
\hline
\end{tabular}

Figures in parentheses express the results of apical ( \pm anterior/inferior) dyskinesia.

*Significant differences $\left(\chi^{2}=8 \cdot 8, P<0.01\right.$, degrees of freedom, 1$)$.

i.e. $\mathrm{Q}$ waves II and AVF ( \pm III). However, it may sometimes be associated with an anterior infarction pattern and also with both patterns. This has important implications since the presence of both inferior and anterior infarction patterns may be considered to indicate several myocardial infarctions with extensive anterior and inferior dyskinesia and triple vessel disease, whereas only one or 2 coronary arteries may be involved with apical dyskinesia.

Based on Einthoven's triangle and the usual electrical axis, it can be seen why apical dyskinesia is associated with an inferior infarction pattern. Although the position of the heart in the thorax may be related to electrical axis, particularly if it is horizontal (Lepeschkin, 1979), no definite evidence for this association could be found because the range of variation of the long axis of the ventricle was limited. The anterior infarction patterns in association with apical dyskinesia could be due to superior angulation of the apex, but rotation forwards of the apex is also possible. It is well known that left anterior hemiblock may develop during acute anterior infarction, probably owing to septal infarction. Although patients with overt left anterior hemiblock were excluded from this study, lesser degrees of left axis deviation could have been due to conduction defects. Then the association of horizontal axis and apical dyskinesia even in association with inferior dyskinesia could be due to associated and unknown septal infarction; such conduction defects might abbreviate anterior forces and so anterior infarction patterns would be more easily produced.

Although the authors have stressed the appearance of anterior infarction patterns in many patients with apical dyskinesia (even in the absence of anterior dyskinesia) and their association with horizontal electrical axes, $Q$ waves in all of the leads $V_{1}$ to $V_{4}$ were always associated with anterior dyskinesia.

The apex appears to be a watershed between the blood supply of the 3 coronary vessels. In view of the usual right coronary dominance in man apical infarction is usually due to right and/or left anterior descending coronary artery disease. Presumably, either single vessel disease associated with inadequate or delayed collateral circulation from the other coronary arteries may produce such apical infarction and thus dyskinesia.

\section{References}

Gunnar, R.M., Pietras, R.J., Blackaller, J., Dadmun, S.E., Szanto, P.B. \& Tobin, J.R. (1967) Correlation of vectorcardiographic criteria for myocardial infarction with autopsy findings. Circulation, 35, 158.

Hugenholtz, P.G., Forkner Jr, C.E. \& Levine, H.D. (1961) A clinical appraisal of the vectorcardiogram in myocardial infarction. II. The Frank system. Circulation, 24, 825.

LEPESCHKIN, E. (1979) Correlation between electrocardiographic and roentgenologic heart measurements. 5th International Congress on Electrocardiology, Glasgow, Sept 1978. Abstract 11.4. (In press.)

ReCKe, S.H., Dacians, Fleck, E. \& Rudolph, W. (1978) Reliability of Frank lead yQ/R ration, $Q$ wave parameters and sagittal plane $Q$ loop rotation in the assessment of extent and severity of left ventricular asynergies in coronary artery disease. 4th International Congress on Electrocardiology, 1977. In: Modern Electrocardiology. London, p. 447.

Talbot, S., Dreifus, L.S., Watanabe, Y., Chiang, R., MORRIS, K. \& REICH, M.B. (1976) Diagnostic criteria for a computer-aided electrocardiographic system. British Heart Journal, 38, 1247.

TAlbot, S., Kilpatrick, D., Jonathan, A. \& Raphael, M.J. (1978) QRS voltage of the electrocardiogram and Frank vectorcardiogram in relation to ventricular volume. 4th International Congress on Electrocardiology, 1977. In: Modern Electrocardiology. London, p. 355. 